\title{
Shining a light in the black box of orphan drug pricing
}

Eline Picavet ${ }^{1 *}$, Thomas Morel ${ }^{1}$, David Cassiman ${ }^{2}$ and Steven Simoens ${ }^{1}$

\begin{abstract}
Background: The pricing mechanism of orphan drugs appears arbitrary and has been referred to as a "black box". Therefore, the aim of this study is to investigate how drug-and disease-specific variables relate to orphan drug prices. Additionally, we aim to explore if certain country-specific pricing and reimbursement policies affect the price level of orphan drugs.

Methods: Annual treatment costs per indication per patient were calculated for 59 orphan drugs with a publicly available price in Belgium, the Netherlands, Czech Republic, France, Italy and the United Kingdom. A multiple linear regression model was built with 14 drug- and disease-specific variables. A Mann-Whitney $U$ test was used to explore whether there is a correlation between annual treatment costs of orphan drugs across countries with different pricing and reimbursement policies.
\end{abstract}

Results: Repurposed orphan drugs, orally administered orphan drugs or orphan drugs for which an alternative treatment is available are associated with lower annual treatment costs. Orphan drugs with multiple orphan indications, for chronic treatments or for which an improvement in overall survival or quality-of-life has been demonstrated, are associated with higher annual treatment costs. No association was found between annual treatments cost of orphan drugs across countries and the different pricing and reimbursement systems.

Conclusions: This study has shown that prices of orphan drugs are influenced by factors such as the availability of an alternative drug treatment, repurposing, etc. Current debate about the affordability of orphan drugs highlights the need for more transparency in orphan drug price setting.

Keywords: Pricing, Price setting, Orphan drugs

\section{Background}

Recently, the price of some orphan drugs has become an issue of much debate. For example, eculizumab, for the treatment of paroxysmal nocturnal hemoglobinuria, can cost up to US\$ 500,000 per patient per year [1]. A few orphan drugs even qualify as blockbusters, as their global annual sales exceed a billion US\$ [2]. Today, third-party payers are increasingly cost-conscious and concerned with escalating health care costs [1]. A Belgian study showed that the impact of orphan drugs is substantial (i.e. amounting to $1.9 \%$ of pharmaceutical expenditure in 2008) and likely to rise significantly in the future [3]. An analysis by Schey et al. predicted that the expenditure on orphan drugs, as a proportion of total pharmaceutical

\footnotetext{
*Correspondence: eline.picavet@pharm.kuleuven.be

'KU Leuven Department of Pharmaceutical and Pharmacological Sciences, Herestraat 49, PO box 521, Leuven 3000, Belgium

Full list of author information is available at the end of the article
}

expenditure, is likely to plateau between four and five percent [4]. Given current budgetary constraints and concerns about affordability, it is likely that the price and price setting of expensive medicines, such as orphan drugs, will become the focus of attention.

Not much is known about the pricing of orphan drugs, the pricing mechanism has even been referred to as a "black box" $[5,6]$. Pricing of orphan drugs is unique because R \& D costs need to be recouped from a small number of patients, also, orphan drugs benefit from a period of market exclusivity and there are few alternatives available [7]. Today, only a few descriptive studies have identified a number of individual factors driving orphan drug price setting. For example, an inverse correlation between the price per capita of an orphan drug and the prevalence of the indication has been reported in the literature. The rarer the indication, the more expensive the 
treatment is $[7,8]$. In contrast, production costs, molecular complexity and therapeutic benefit have not been found to correlate with the price of an orphan drug [6]. A recent study regrouped orphan drugs in four categories, i.e. firstto-market non-oncology orphan drugs, second-to-market non-oncology orphan drugs, repurposed non-oncology drugs and oncology orphan drugs. The annual weighted treatment costs of drugs in the first category, accounting for $44 \%$ of all orphan drugs, are in the highest range, with an average cost of $€ 200,000$ per patient per year. Mean annual treatment costs of drugs in the other categories range between $€ 16,000$ and $€ 35,000$ [9].

To the best of the authors' knowledge, no recent studies have investigated how annual treatment costs relate to different drug-, disease- and country-specific variables. The use of annual treatment costs has become an accepted method to compare prices. For example, Messori et al. used yearly cost per patient to define the inverse relation between price and prevalence [8]. Orofino et al. calculated mean annual treatment cost per patient to estimate spending on orphan drugs in several European countries [10]. Aballéa et al. found that low disease prevalence and low number of available therapeutic alternatives are associated with a higher annual treatment cost. However, no significant association was found between any other disease-related and drug-related variables and yearly treatment cost, possibly due to a lack of power [11]. Prices for orphan drugs also vary across countries due to different pricing and reimbursement policies (e.g. free vs. fixed pricing) [12]. Although national pricing mechanisms are often not specific to orphan drugs, they do tend to favor orphan drugs, for example, by setting up special funds for reimbursement $[5,13]$.

The aim of this study is to investigate how various drugand disease-specific variables relate to annual treatment costs per patient and per orphan drug indication in six European countries. Additionally, we aim to explore if certain country-specific pricing and reimbursement policies affect the price level of orphan drugs.

\section{Methods}

All orphan drugs, listed as authorized on the website of the European Medicines Agency on April 172013 (n=65) and for which a price was publicly available in Belgium, the Netherlands, Czech Republic, France, Italy or the United Kingdom were included in the analysis [14].

\section{Annual treatment dose}

The annual treatment dose was calculated per indication according to the standard treatment plan described in the Summary of Product Characteristics (SmPC). If a starting dose was adjusted based on (unknown) performance results (e.g. for mecasermin (Increlex $\left.{ }^{\odot}\right)$ ), the initial starting dose was maintained. If a dose range was given (e.g. for romiplostim $\left(\right.$ Nplate $\left.^{\oplus}\right)$ ), then an average dose between the minimum and maximum dose was assumed. No dose adjustments were carried out to account for liver and/or kidney impaired patients. To determine the weight or Body Surface Area (BSA) necessary to calculate the dose of weight-adjusted and BSA-adjusted treatments, weight and/or height information from pivotal studies as described in the European Public Assessment Report (EPAR) were consulted at first. Secondly, patient registries (e.g. from the European Organisation for Research and Treatment of Cancer) or relevant studies, as described on clinicaltrials.gov or in publications were consulted. As a last resort, weight and/or height data was derived from standardized growth curves $[15,16]$. BSA was determined using the Haycock formula, a validated method for calculating BSA in infants, children and adults [17]. The annual treatment dose for children was calculated conservatively, by assuming the lowest age (in accordance with the registered indication) and no weight and/or height increase over the course of a year.

Treatment duration of 365 days was assumed, unless stated differently in the SmPC. For treatments given in cycles, the total number of cycles was based on the treatment plan. In case of varying numbers of cycles, the mean number of cycles in the main clinical study (as described in the EPAR) was assumed. In case of incatibant $\left(\right.$ Firazyr ${ }^{\odot}$ ), the number of cycles was calculated based on the chance distributions described in the EPAR. In the absence of data on the number of cycles, the number of cycles was derived from the Overall Survival (OS) time (e.g. for temsirolimus $\left(\right.$ Torisel $\left.^{\oplus}\right)$ ).

\section{Annual treatment cost}

Orphan drug prices were analysed in six European countries (Belgium, the Netherlands, Czech Republic, France, Italy and the United Kingdom), which were selected based on public availability of orphan drug prices (Table 1). Prices in Czech koruna (CZK) and British pound sterling (GBP) were converted into Euro by applying the exchange rates of respectively $€ 1=25.95$ CZK (July 2013) and $€ 1=0.83$ GBP (October 2013) [18]. The gross domestic products (GDP) per capita in purchasing power standard (PPS) of these countries are of similar magnitude, therefore allowing international comparison (Table 1) [19]. The EU28 index equals 100 (standard deviation $=41.33$ ) and varies from 47 in Bulgaria to 263 in Luxemburg.

Annual treatment costs (ATX) were calculated per patient per orphan drug indication and per country based on the annual treatment dose and the most recent price in each country. Vial wastage was assumed. If there was an unfinished pack at the end of the year, only a proportion of the price of that pack was accounted for. In case of multiple packaging sizes, the cheapest pack (or a combination of packs) was selected. Annual treatment 
Table 1 Pricing data per country

\begin{tabular}{|c|c|c|c|c|c|c|c|}
\hline & $\begin{array}{l}\text { GDP per } \\
\text { capita in PPS }\end{array}$ & Source of price data & & $\begin{array}{l}\text { Date of data } \\
\text { extraction }\end{array}$ & $\begin{array}{l}\text { Number of } \\
\text { orphan drugs }\end{array}$ & Type of price* & $\begin{array}{l}\text { Distribution } \\
\text { channel [20] }\end{array}$ \\
\hline Belgium & 120 & $\begin{array}{l}\text { Belgian Centre for } \\
\text { Pharmacotherapeutic } \\
\text { Information }\end{array}$ & [21] & $17 / 04 / 2013$ & 41 & Public prices & Hospital pharmacies \\
\hline Netherlands & 128 & $\begin{array}{l}\text { College voor } \\
\text { Zorgverzekeringen }\end{array}$ & {$[22]$} & $26 / 07 / 2013$ & 40 & $\begin{array}{l}\text { Consumer } \\
\text { reimbursement prices }\end{array}$ & $\begin{array}{l}\text { Hospital and } \\
\text { community pharmacies }\end{array}$ \\
\hline $\begin{array}{l}\text { Czech } \\
\text { Republic }\end{array}$ & 81 & $\begin{array}{l}\text { SÚKL State Institute } \\
\text { for Drug Control }\end{array}$ & [23] & 29/07/2013 & 29 & $\begin{array}{l}\text { Rough prices for final } \\
\text { consumer }\end{array}$ & Hospital pharmacies \\
\hline France & 109 & Thériaque & {$[24]$} & $25 / 07 / 2013$ & 43 & $\begin{array}{l}\text { Mixed prices: } \\
\text { taxes excluded } \\
\text { and taxes included }\end{array}$ & Hospital pharmacies \\
\hline \multirow[t]{2}{*}{ Italy } & \multirow[t]{2}{*}{101} & Informazioni Sui Farmaci & {$[25]$} & $30 / 07 / 2013$ & \multirow[t]{2}{*}{21} & Ex-factory prices & \multirow{2}{*}{$\begin{array}{l}\text { Hospital and } \\
\text { community } \\
\text { pharmacies }\end{array}$} \\
\hline & & $\begin{array}{l}\text { Agenzia Italiana } \\
\text { del Farmaco }\end{array}$ & {$[26]$} & $02 / 08 / 2013$ & & Maximum prices & \\
\hline $\begin{array}{l}\text { United } \\
\text { Kingdom }\end{array}$ & 106 & $\begin{array}{l}\text { British National } \\
\text { Formulary } 2013\end{array}$ & {$[27]$} & $02 / 10 / 2013$ & 50 & Net cost & Hospital pharmacies \\
\hline
\end{tabular}

GDP: gross domestic product, PPS: purchasing power standard, *type of prices: as described by data source: "public prices", "consumer reimbursement prices", "rough prices for final consumer" and "maximum prices" represent ex-factory prices increased by a distribution margin for the wholesaler, a distribution margin for the pharmacist, taxes and honoraria. "Ex-factory prices" and "net cost" are ex-factory prices without taxes and margins for distributers and pharmacists [28]. Due to differences in margins, taxes and negotiations, pricing of orphan drugs may differ dependent on the distribution channel.

costs of various formulations of the same orphan drug were calculated separately. No official prices were found for ivacaftor (Kalydeco ${ }^{\circ}$ ), alipogene tiparvovec (Glybera ${ }^{\circ}$ ), concentrate of proteolytic enzymes enriched in bromelain $\left(\mathrm{NexoBrid}^{\circ}\right)$ and teduglutide (Revestive $\left.{ }^{\circ}\right)$ in any of the six countries. Additionally, we were unable to calculate the annual treatment cost for hydroxycarbamide (Siklos ${ }^{\circ}$ ) and sapropterin dihydrochloride $\left(\operatorname{Kuvan}^{\circ}\right)$ due to the patient-specific nature of those treatments.

\section{Statistical analysis}

Table 2 provides an overview of the explanatory drug- and disease-specific variables and the various data sources. Drug-specific variables relate to an aspect of the drug itself, (e.g. on the type of formulation), whereas diseasespecific variables describe aspects of the indication for which the drug is used (e.g. the availability of an alternative treatment). Explanatory variables were selected after a review of the literature. Relevant literature was identified by searching the MEDLINE and Embase databases. The following search terms and combinations thereof were used: orphan drug, orphan medicinal product, rare disease, rare disorder, cost, price, pricing, policies, price-setting, market access, and budget. For practical reasons, all selected articles were published in English, French or Dutch. Bibliographies of relevant articles were searched for additional references. Afterwards, variables were selected based on the availability of data related to each variable. For example, the literature indicates that severity of the diseases could be related to price; however, there is no reliable data available for rare diseases on disease severity that can be used in a regression analysis $[1,5-8,10,29-36]$. The common logarithms of the annual treatment costs per country were considered the outcome variables given that the original cost data were not normally distributed. Firstly, a simple linear regression analysis was performed in which all explanatory variables were individually analysed to determine a linear relation with the outcome variables. All explanatory variables, with a p-value below 0.05 in the simple linear regression analysis, were included in the multiple linear regression analysis. The multiple linear regression models were reduced stepwise by removing variables with significance levels above the 0.05 threshold. Variables with borderline significant p-values were tolerated with a view to obtaining a higher coefficient of determination $\left(R^{2}\right)$. All analyses were performed using IBM SPSS Statistics version 22.

Additionally, the potential treatment population was calculated per orphan drug, per country and at the EU28 level by multiplying the prevalence of the indication as described in the European Public Assessment Report and/ or Orphanet website with recent population data from the six countries and the EU28 as derived from Eurostat [19]. For orphan drugs with multiple indications, potential treatment populations of separate indications were summarized.

\section{Influence of country-specific pricing and reimbursement policies}

The independent samples Mann-Whitney $U$ test was used to explore whether there is an association between annual treatment costs of orphan drugs across countries with different pricing and reimbursement policies. The Mann-Whitney $U$ test determines whether the overall distribution of annual treatment costs in one group (e.g. in countries with free pricing) is greater or smaller than the other (e.g. in countries with fixed pricing). Table 3 provides 
Table 2 Regression model - explanatory variables

\begin{tabular}{|c|c|c|}
\hline Variable & Value & Description and source \\
\hline ONCO & 0 or 1 & $\begin{array}{l}\text { Value } 1 \text { renders all oncology orphan drugs. Oncology orphan drugs were defined as ATC-class L } \\
\text { (Antineoplastic and immunomodulating agents). }\end{array}$ \\
\hline YAUTH & Continuous & Number of years (as an integer number) since marketing authorization of the first indication by EMA. \\
\hline AvailUS & 0 or 1 & $\begin{array}{l}\text { Value } 1 \text { renders all orphan drugs with current authorization on the US market as listed by the FDA. } \\
\text { AvailUS is a proxy for size of the potential treatment population. [37] }\end{array}$ \\
\hline MultipleIND & 0 or 1 & $\begin{array}{l}\text { Value } 1 \text { renders all drugs with multiple orphan indications according to EMA. MultipleIND is a proxy } \\
\text { for size of the potential treatment population. }\end{array}$ \\
\hline REPUR & 0 or 1 & Value 1 captures all repurposed drugs. [38] \\
\hline QoLimp & 0 or 1 & $\begin{array}{l}\text { Value } 1 \text { renders all drugs for which a statistically significant improvement in quality-of-life was described } \\
\text { in the European Public Assessment Report. }\end{array}$ \\
\hline Survlmp & 0 or 1 & $\begin{array}{l}\text { Value } 1 \text { captures all drugs for which a statistically significant improvement in survival was described in } \\
\text { the European Public Assessment Report. }\end{array}$ \\
\hline $\mathrm{dbRCT}$ & 0 or 1 & $\begin{array}{l}\text { Value } 1 \text { renders all drugs for which a double blind RCT was described in the European Public Assessment } \\
\text { Report. dbRCT is a proxy for strength of clinical trial evidence. }\end{array}$ \\
\hline AltTx & 0 or 1 & $\begin{array}{l}\text { Value } 1 \text { renders all drugs for which an alternative drug treatment is available. Supportive care, diet, } \\
\text { palliative care, transplantation and surgical procedures were not considered as an alternative. }\end{array}$ \\
\hline ultrarare & 0 or 1 & $\begin{array}{l}\text { Value } 1 \text { renders all drugs treating ultra-rare diseases. Ultra rare diseases have a prevalence of less than } 2 \\
\text { per } 100000 \text { as described in the European Public Assessment Report and/or Orphanet website. }\end{array}$ \\
\hline chron & 0 or 1 & Value 1 renders all drugs for chronic (i.e.; longer than 6 months) treatments. \\
\hline oral & 0 or 1 & Value 1 captures all oral drugs. \\
\hline Cosize & 0 or 1 & $\begin{array}{l}\text { Cosize refers to the company size of the marketing authorization holder: respectively micro and small (0) } \\
\text { and medium and large (1) pharmaceutical companies. Company size is based on the European definition } \\
\text { described in EU recommendation 2003/361. Data on annual sales was derived from OneSource. [39] }\end{array}$ \\
\hline Weightbased & 0 or 1 & $\begin{array}{l}\text { Value } 1 \text { captures all drugs for which the annual treatment dose is dependent on the patient's weight or } \\
\text { body surface area (BSA) }\end{array}$ \\
\hline
\end{tabular}

an overview of the different policies per country: freemarket pharmaceutical pricing or price regulation (free pricing may result in higher prices for drugs); a social insurance or national health services reimbursement system; the absence or presence of a Health Technology Assessment (HTA) body; and the absence or presence of cost-effectiveness criteria when assessing orphan drug reimbursement [5]. In countries with a low GDP, budgetary restrictions can cause the exclusion of less cost-effective orphan drugs [40-43].

Various countries apply innovative reimbursement mechanisms, so-called 'managed entry agreements' (MEAs), to orphan drugs. The existence of a MEA has been documented for some orphan drugs in Belgium, England and Wales, Italy and the Netherlands by Morel et al. [44]. Therefore, a simple linear regression analysis was performed to determine whether the existence of a MEA for an orphan drug $(0-1$ variable) is associated with higher or lower annual treatment costs in these countries.

\section{Results}

\section{Simple linear regression}

At significance threshold level 0.05 , ten explanatory variables appeared to play a role in the price setting of orphan drugs (Table 4). Orphan drugs which are also available in the US (1), with multiple orphan indications (2), for chronic treatments (3), for which an improvement in QoL (4) or survival (5) has been demonstrated or for ultrarare indications (6) are correlated with higher annual treatment costs. Orphan drugs for which an alternative treatment is available (7), which are repurposed (8), which are administered orally (9), or for which the market

Table 3 Pricing and reimbursement policies per country

\begin{tabular}{|c|c|c|c|c|c|c|}
\hline & Belgium & France & Netherlands & Czech Republic & Italy & United Kingdom \\
\hline Pricing & Price negotiations & Price negotiations & Price negotiations & Fixed & Price negotiations & $\begin{array}{l}\text { Free, but indirect profit } \\
\text { control system }\end{array}$ \\
\hline Reimbursement & $\mathrm{SI}$ & $\mathrm{SI}$ & $\mathrm{SI}$ & $\mathrm{SI}$ & $\mathrm{NHS}$ & $\mathrm{NHS}$ \\
\hline HTA body & $\checkmark$ & $\checkmark$ & $\checkmark$ & $x$ & $x$ & $\checkmark$ \\
\hline Cost-effectiveness & $x$ & $x$ & $\checkmark$ & $\checkmark$ & $x$ & $\checkmark$ \\
\hline
\end{tabular}

SI: Social insurance, NHS: National Health Service. 
Table 4 Simple linear regression analysis

\begin{tabular}{|c|c|c|c|c|c|c|c|c|c|c|c|c|}
\hline \multirow[b]{2}{*}{ Variable (x) } & \multicolumn{2}{|c|}{$\begin{array}{c}\text { Belgium } \\
\mathrm{n}=51\end{array}$} & \multicolumn{2}{|c|}{$\begin{array}{l}\text { France } \\
\mathrm{n}=59\end{array}$} & \multicolumn{2}{|c|}{$\begin{array}{l}\text { Netherlands } \\
n=52\end{array}$} & \multicolumn{2}{|c|}{$\begin{array}{l}\text { Czech Republic } \\
\qquad n=41\end{array}$} & \multicolumn{2}{|c|}{$\begin{array}{c}\text { Italy } \\
n=28\end{array}$} & \multicolumn{2}{|c|}{$\begin{array}{l}\text { United Kingdom } \\
\qquad \mathrm{n}=66\end{array}$} \\
\hline & $\log B e A T X \cos t=$ & $\mathrm{p}$-value & $\log F r A T X \cos t=$ & $\mathrm{p}$-value & $\operatorname{logNIATX} \cos t=$ & p-value & $\log C z A T X \cos t=$ & $p$-value & logltATX $\cos t=$ & $\mathrm{p}$-value & $\log U k A T X \cos t=$ & $\mathrm{p}$-value \\
\hline Cosize & $4.422-0.214 x$ & 0.329 & $4.449-0.175 x$ & 0.360 & $4.033+0.258 x$ & 0.176 & $4.647-0.520 x$ & $0.015^{*}$ & $4.534-0.228 x$ & 0.477 & $4.505-0.115 x$ & 0.465 \\
\hline ONCO & $4.290+0.007 x$ & 0.973 & $4.321+0.081 x$ & 0.677 & $4.000+0.313 x$ & 0.107 & $4.270+0.203 x$ & 0.361 & $4.573-0.326 x$ & 0.305 & $4.414+0.040 x$ & 0.804 \\
\hline YAUTH & $4.584-0.042 x$ & 0.406 & $4.664-0.049 x$ & 0.220 & $4.396-0.044 x$ & 0.196 & $4.765-0.060 x$ & 0.267 & $4.519-0.006 x$ & 0.942 & $4.665-0.039 x$ & 0.204 \\
\hline AvailUS & $3.837+0.600 x$ & $0.014^{*}$ & $3.829+0.661 x$ & $0.004^{*}$ & $3.967+0.242 x$ & 0.234 & $4.078+0.399 x$ & 0.104 & $3.973+0.543 x$ & 0.328 & $4.240+0.250 x$ & 0.189 \\
\hline MultipleIND & $4.159+0.558 x$ & $0.024^{*}$ & $4.142+0.645 x$ & $0.001 *$ & $3.980+0.760 x$ & $0.001 *$ & $4.277+0.277 x$ & 0.241 & $4.277+0.595 x$ & $0.047^{*}$ & $4.292+0.455 x$ & $0.007^{*}$ \\
\hline REPUR & 4.473-0.816x & $0.001 *$ & $4.495-0.684 x$ & $0.003^{*}$ & $4.324-0.711 x$ & $0.000^{*}$ & $4.502-0.771 x$ & $0.006^{*}$ & $4.505-0.793 x$ & 0.303 & $4.558-0.545 x$ & $0.003^{*}$ \\
\hline QoLimp & $4.239+0.451 x$ & 0.171 & $4.248+0.556 x$ & $0.019^{*}$ & $4.066+0.535 x$ & 0.069 & $4.313+0.427 x$ & 0.200 & $4.313+0.628 x$ & 0.052 & $4.368+0.348 x$ & $0.090^{*}$ \\
\hline Survimp & $4.242+0.321 x$ & 0.274 & $4.344+0.069 x$ & 0.803 & $4.048+0.592 x$ & $0.031 *$ & $4.255+0.497 x$ & 0.057 & $4.424+0.350 x$ & 0.394 & $4.391+0.206 x$ & 0.303 \\
\hline $\mathrm{dbRCT}$ & $4.341-0.089 x$ & 0.682 & $4.389-0.068 x$ & 0.724 & $4.265-0.278 x$ & 0.146 & $4.562-0.390 x$ & 0.074 & $4.435-0.085 x$ & 0.772 & $4.440-0.017 x$ & 0.915 \\
\hline altTX & $5.000-0.883 x$ & $0.001 *$ & $4.919-0.782 x$ & $0.000^{*}$ & $4.471-0.436 x$ & 0.059 & $4.958-0.676 x$ & $0.039 *$ & $5.098-0.988 x$ & $0.000^{*}$ & $4.906-0.669 x$ & $0.000^{*}$ \\
\hline Ultrarare & $4.200+0.303 x$ & 0.171 & $4.245+0.295 x$ & 0.132 & $4.132+0.163 x$ & 0.420 & $4.381+0.086 x$ & 0.752 & $4.281+0.353 x$ & 0.249 & $4.347+0.193 x$ & 0.249 \\
\hline Chronic & $3.883+0.554 x$ & $0.021 *$ & $3.954+0.493 x$ & $0.040^{*}$ & $3.963+0.228 x$ & 0.289 & $4.310+0.073 x$ & 0.785 & $3.947+0.620 x$ & 0.124 & $4.114+0.414 x$ & $0.027^{*}$ \\
\hline Weightbased & $4.185+0.216 x$ & 0.315 & $4.289+0.142 x$ & 0.458 & $4.231-0.209 x$ & 0.276 & $4.222+0.305 x$ & 0.167 & $4.346+0.351 x$ & 0.242 & $4.321+0.235 x$ & 0.143 \\
\hline Oral & $4.563-0.500 x$ & $0.018^{*}$ & 4.609-0.449x & $0.017^{*}$ & $4.154-0.040 x$ & 0.840 & $4.650-0.540 x$ & $0.012^{*}$ & $4.705-0.411 x$ & 0.156 & $4.623-0.400$ & $0.011^{*}$ \\
\hline
\end{tabular}

Explanatory variables are described in Table 2. $\mathrm{N}$ denotes the number of observations. All p-values marked in bold with an asterisk are significant at a 0.05 threshold level. ATXcost $=$ annual treatment cost. 
authorization holder (MAH) is a medium- or largesized pharmaceutical company (10) are associated with lower annual treatment costs. The Spearman test for nonparametric bivariate correlations showed a correlation coefficient $(r h o)$ of -0.408 (2-sized $\mathrm{p}=0.000)$ between variables 'ultra-rare indication' and 'alternative treatment', and a rho of 0.309 ( $\mathrm{p}=0.007)$ between 'oral' and 'chronic', suggesting a mild correlation between these variables. Only a strong correlation $(|r h o|>0.7)$ between variables implies that one of them should be omitted from the analysis.

\section{Multiple linear regression}

The multiple linear regression models showed, after stepwise reduction, significant associations between in total seven explanatory variables and the logarithm of the average annual treatment costs in different countries (Table 5). Again, repurposed orphan drugs, orally administered orphan drugs or orphan drugs for which an alternative treatment is available are associated with lower annual treatment costs. Orphan drugs with multiple orphan indications, for chronic treatments or for which an improvement in overall survival or QoL has been demonstrated, are associated with higher annual treatment costs. An average $\mathrm{R}^{2}$ of 0.674 was obtained, suggesting that the variables above explain around $67.5 \%$ of the variability in orphan drug annual treatment costs. Results from the Czech and Italian regression model may be underpowered, due to the smaller number of observations.

Finally, the independent samples Mann-Whitney $U$ test showed a significantly larger potential treatment population $(\mathrm{p}=0.034)$ in all countries and in the EU28 for orphan drugs with multiple orphan indications compared to orphan drugs with one orphan indication.

\section{Influence of country-specific pricing and reimbursement policies}

No association was found between annual treatment cost of orphan drugs across countries and the pricing system $(p=0.209)$, the reimbursement system $(p=0.122)$, the availability of an HTA body $(\mathrm{p}=0.408)$ or the requirement of cost-effectiveness at reimbursement $(\mathrm{p}=0.791)$. Finally, the simple linear regression analysis showed no significant association between the annual treatment costs of orphan drugs and the existence of MEAs for specific orphan drugs in Belgium ( $p=0.803)$, England and Wales $(p=0.215)$, Italy $(\mathrm{p}=0.805)$ and the Netherlands $(\mathrm{p}=0.071)$.

\section{Discussion}

This study has identified various determinants of pricing of orphan drugs. The multiple linear regression models show significant associations between the average annual treatment cost and seven explanatory variables. Furthermore, our results seem to suggest that there are no large variations in orphan drug prices between countries in this study, in spite of differences in pricing and reimbursement policies. The annual treatment cost per patient of $18 \%$ of orphan drugs in this study exceeds $€ 100000$.

Firstly, orphan drugs with multiple orphan indications are associated with higher prices. These results suggest that the combined prevalence is not a determining factor for price setting. Indeed, previous research showed that orphan drug prices are determined based on the prevalence of the first indication [36,45]. Launch prices for the first indication are unlikely to be reviewed following approval in other indications [46]. We calculated that orphan drugs with multiple indications have a significantly larger potential market size, although it is essential to bear in mind that no correct estimates of prevalence exist and not all patients are diagnosed and/or treated [47]. As such, the larger potential market size, combined with the higher prices for these drugs, increase the likelihood of these drugs becoming sufficiently profitable. The European regulation provides a framework for the reduction of the period of market exclusivity for orphan drugs which are sufficiently profitable, but it has never been put into practice $[36,48]$. There is growing concern about the increasing prices of (orphan) drug treatments [49]. For example, the median monthly price of anticancer drugs increased from US\$1,600 in the early 1990 s, to more than US\$ 4,000 for anticancer drugs approved between 2000 and 2005 [50]. However, we could not confirm a correlation between the price of orphan drugs and the number of years since marketing authorization.

Secondly, repurposed orphan drugs are associated with lower prices. Rollet et al. also showed that the average annual treatment cost was the lowest for the category of repurposed orphan drugs [9]. It was suggested that the price of the initial common disease indication influences the price of a repurposed orphan drug. In contrast, a study in which Belgian hospital prices per defined daily dose of the medicine for the common indication versus the rare indication were compared, price differences of up to 200-fold were reported. However, this study related to a specific subset of repurposed drugs for which the effectiveness evidence was already established prior to the orphan designation [38].

Under the soon-to-be introduced value-based pricing (VBP) system by NICE in the UK, all new medicines will be priced according to their value. A study suggests that diseases for which no other treatments are available represent an unmet need and should be prioritized under the VBP system [51]. Indeed, unmet need (i.e. the absence of alternative treatments), therapeutic benefit (i.e. QoL or survival improvement) and therapeutic value (i.e. high quality of clinical trial data, ease of administration) could warrant high (er) prices. Our results show that the availability of an alternative drug treatment is associated with lower prices for orphan drugs. In the past, only a 
Table 5 Country-specific multiple linear regression models after stepwise reduction

\begin{tabular}{|c|c|c|c|c|c|c|c|c|c|c|c|c|}
\hline \multirow[b]{2}{*}{ Variable $(x)$} & \multicolumn{2}{|c|}{$\begin{array}{l}\text { Belgium } \\
\mathrm{R}^{2}=0.739 \mathrm{n}=51 \\
\text { Constant }=4.734\end{array}$} & \multicolumn{2}{|c|}{$\begin{array}{c}\text { France } \\
\mathrm{R}^{2}=0.716 \mathrm{n}=59 \\
\text { Constant }=4.911\end{array}$} & \multicolumn{2}{|c|}{$\begin{array}{c}\text { Netherlands } \\
\mathrm{R}^{2}=0.570 \mathrm{n}=52 \\
\text { Constant }=4.170\end{array}$} & \multicolumn{2}{|c|}{$\begin{array}{c}\text { Czech republic } \\
\mathrm{R}^{2}=0.706 \mathrm{n}=41 \\
\text { Constant }=4.329\end{array}$} & \multicolumn{2}{|c|}{$\begin{array}{c}\text { Italy } \\
\mathrm{R}^{2}=0.656 \mathrm{n}=28 \\
\text { Constant }=5.098\end{array}$} & \multicolumn{2}{|c|}{$\begin{array}{l}\text { United Kingdom } \\
\mathrm{R}^{2}=0.661 \mathrm{n}=66 \\
\text { Constant }=4.652\end{array}$} \\
\hline & Unstand. coeff. & $p$-value & Unstand. coeff. & $p$-value & Unstand. coeff. & $\overline{p \text {-value }}$ & Unstand. coeff. & $p$-value & Unstand. coeff. & $p$-value & Unstand. coeff. & $p$-value \\
\hline MultipleIND & & & 0.504 & 0.001 & 0.570 & 0.010 & & & & & 0.312 & 0.028 \\
\hline Repurposed & -0.573 & 0.006 & -0.548 & 0.002 & -0.557 & 0.005 & -0.656 & 0.006 & & & -0.325 & 0.039 \\
\hline altTx & -0.478 & 0.026 & -0.584 & 0.001 & & & & & -0.988 & 0.000 & -0.397 & 0.011 \\
\hline Oral & -0.637 & 0.000 & -0.328 & 0.023 & & & -0.678 & 0.001 & & & -0.392 & 0.006 \\
\hline Survimp & & & & & & & 0.443 & 0.035 & & & & \\
\hline Chronic & 0.464 & 0.025 & & & & & 0.445 & 0.044 & & & 0.296 & 0.089 \\
\hline ImprovQoL & 0.565 & 0.021 & & & & & 0.509 & 0.060 & & & & \\
\hline
\end{tabular}


non-significant trend has been reported between the number of available alternatives for an orphan drug and its price [11]. Also, orphan drugs for which an improvement in survival and/or QoL has been demonstrated, are associated with higher prices. Roos et al. claim that the therapeutic benefit of an orphan drug does not correlate with its price [6]. Due to difficulties in generating evidence to demonstrate therapeutic benefit, this information is often lacking or incomplete when the price is set. We found no association between the existence of a double blind RCT and the price of an orphan drug. A more in-depth analysis of clinical trial data is required. From the patients' point of view, the ease of administration of an oral drug constitutes a considerable therapeutic value as some intravenous or inhalation therapies can be time-consuming. Our results correlate oral orphan drugs with lower prices and chronic treatments with higher prices. Popular media claimed that the most expensive drugs are injectable drugs whose dosing varies by weight [52]. Our results indicate that indeed, oral orphan drugs are cheaper. However, we could not confirm a correlation between weight-dependent dosing and price.

Finally, we found no correlation between different pricing and reimbursement policies and the annual treatment cost of orphan drugs across countries in this study. However, as countries in this study likely have a similar ability to pay for orphan drugs, we cannot conclude that there is a trend towards uniform pricing of orphan drugs in Europe. Additionally, many countries have special regulations governing orphan drugs market [40]. For example, in France, Italy and the Netherlands, there are specific policy measures and incentives to promote research and development of orphan drugs [20]. In England, some orphan drugs are funded by the national Cancer Drug Fund from the National Health Services [53]. In the Netherlands, hospitals are financially supported for prescribing orphan drugs through the Dutch Policy Rule for Expensive Hospital and Orphan Drugs [54]. A differential pricing system, in which price is dependent on a country's GDP, could enhance equal access to orphan drugs [29]. However, the success of differential pricing depends on the ability to limit parallel export between countries [55]. Prices obtained after country-specific price negotiations or in MEAs are not captured by this study. Higher prices for orphan drugs do not increase the likelihood of a MEA.

This study provides insight into the interplay of orphan drugs pricing and various drug and disease specific explanatory variables. The variables in the multiple linear regression models explain on average $67.5 \%$ of the variability in orphan drug prices. The effects of each variable were considered independently (i.e. no interactions between variables were added to the model), thereby reducing the risk of overfitting. Due to the availability of data, we used a mix of public prices and ex-factory prices, although results tended to be consisted across countries. Final prices are determined based on confidential negotiations with governments and are also influenced by rebates and discounts negotiated with insurers, wholesalers and hospital pharmacies [9]. Negotiated prices are confidential and are likely to show more variability across countries. We were unable to determine whether publicly available prices account for rebates and/or are the result of negotiations. The transformation of some variables to binary variables constitute both a strength and a weakness, as it increases the likelihood of obtaining significant results, but may also oversimplify the analysis. Finally, annual treatment dosages were calculated for "standard" patients without accounting for lower adherence in daily life, lower dosages for liver- and/or renal-impaired patients or other patient-specific dose adjustments. Weights of patients obtained from clinical trial data can possibly be skewed due to the trial inclusion criteria.

\section{Conclusion}

This study has shown that prices of orphan drugs are influenced by factors such as the availability of an alternative drug treatment, repurposing, the length of treatment, the administration route, the presence of multiple indications and the impact on overall survival and QoL. Yet, a lot of vagueness still surrounds the orphan drug pricing mechanism. Current debate about the affordability of high-priced orphan drugs and the impact on accessibility highlights the need for more transparency around orphan drug price setting. Within the context of value-based pricing decisions, a Transparent Value Framework (TVF) has been proposed with a set of indicative assessment criteria [56]. The outcome of a TVF assessment could be included as a factor in pricing negotiations. Unfortunately, countryspecific price negotiations may also add to the complexity of orphan drug pricing.

\section{Abbreviations \\ SmPC: Summary of product characteristics; BSA: Body surface area; EPAR: European public assessment report; OS: Overall survival; HTA: Health technology assessment; MEAs: Managed entry agreements; MAH: Marketing authorization holder; VBP: Value-based pricing; TVF: Transparent value framework.}

\section{Competing interests}

The authors have no conflicts of interest that are directly relevant to the content of this manuscript. Thomas Morel is an employee of UCB. The authors would like to thank Miss Lenka Pavlacka for her assistance in collecting orphan drug prices in the Czech Republic.

\section{Authors' contributions}

The work presented was carried out in collaboration between all authors. EP, $\mathrm{TM}$, and SS were involved in the initiation of the project and the design of the methods. EP and TM participated in the data collection. EP analysed the data and interpreted the results. EP, TM, DC and SS discussed the results. EP and SS wrote the draft paper. All authors revised the draft paper. All authors read and approved the final manuscript.

\section{Acknowledgements}

The authors would like to thank Miss Lenka Pavlacka for her assistance in collecting orphan drug prices in the Czech Republic. 


\section{Author details}

'KU Leuven Department of Pharmaceutical and Pharmacological Sciences, Herestraat 49, PO box 521, Leuven 3000, Belgium. ${ }^{2}$ Department of Hepatology, University Hospital Leuven, Herestraat 49, Leuven 3000, Belgium.

Received: 3 December 2013 Accepted: 14 April 2014 Published: 27 April 2014

\section{References}

1. Meekings KN, Williams CS, Arrowsmith JE: Orphan drug development: an economically viable strategy for biopharma $\mathrm{R} \& \mathrm{D}$. Drug Discov Today 2012, 17:660-664.

2. Wellman-Labadie O, Zhou Y: The US Orphan Drug Act: rare disease research stimulator or commercial opportunity? Health Pol 2010, 95:216-228.

3. Denis A, Mergaert L, Fostier C, Cleemput I, Simoens S: Budget impact analysis of orphan drugs in Belgium: estimates from 2008 to 2013. J Med Econ 2010, 13:295-301.

4. Schey C, Milanova T, Hutchings A: Estimating the budget impact of orphan medicines in Europe: 2. Orphanet J Rare Dis 2011, 6:62.

5. Michel M, Toumi M: Access to orphan drugs in Europe: current and future issues. Expert Rev Pharmacoecon Outcomes Res 2012, 12:23-29.

6. Roos JC, Hyry HI, Cox TM: Orphan drug pricing may warrant a competition law investigation. BMJ 2010, 341:C6471

7. Simoens S: Pricing and reimbursement of orphan drugs: the need for more transparency. Orphanet J Rare Dis 2011, 6:42.

8. Messori A, Cicchetti A, Patregani L: Orphan drugs. BMJ 2010, 341:c4615

9. Rollet $\mathrm{P}$, Lemoine $\mathrm{A}$, Dunoyer $\mathrm{M}$ : Sustainable rare diseases business and drug access: no time for misconceptions. Orphanet J Rare Dis 2013, 8:109.

10. Orofino J, Soto J, Casado MA, Oyaguez I: Global spending on orphan drugs in France, Germany, the UK, Italy and Spain during 2007. Appl Health Econ Health Pol 2010, 8:301-315.

11. Aballea S, Toumi M, Vataire AL, Millier A, Lamure M: Quantitative Analysis of the Influence of Disease and Product Characteristics on Orphan Drug Prices in Europe [abstract]. Value Health 2010, 13:A82.

12. Alcimed: Study on Orphan Drugs - Phase I Overview of the Conditions for Marketing Orphan drugs in Europe. [http://ec.europa.eu/health/files/ orphanmp/doc/pricestudy/final_final_report_part_1_web_en.pdf]

13. Denis A, Mergaert L, Fostier C, Cleemput I, Simoens S: A comparative study of European rare disease and orphan drug markets. Health Pol 2010, 97:173-179

14. European Medicines Agency. [http://www.ema.europa.eu/]

15. Walpole SC, Prieto-Merino D, Edwards P, Cleland J, Stevens G, Roberts I: The weight of nations: an estimation of adult human biomass. BMC Public Health 2012, 12:439.

16. World Health Organisation: WHO Child Growth Standards: Length/heightfor-age, weight-for-age, weight-for-length, weight-for-height and body mass index-for-age: Methods and development. [http://www.who.int/ childgrowth/standards/technical_report/en/]

17. Haycock GB, Schwartz GJ, Wisotsky DH: Geometric method for measuring body surface area: a height-weight formula validated in infants, children, and adults. J Pediatr 1978, 93:62-66.

18. XE The World's Favorite Currency Site. [http://www.xe.com/

19. European Commission: Eurostat. [http://epp.eurostat.ec.europa.eu/portal/ page/portal/eurostat/home/]

20. Denis A, Simoens S, Fostier C, Mergaert L, Cleemput l: Beleid voor zeldzame ziekten en Weesgeneesmiddelen KCE reports 112A. [https://kce.fgov.be/sites/default/files/page_documents/d20091027330.pdf]

21. BCFI - Belgian Centre for Pharmacotherapeutic Information. [http://www.bcfi.be/]

22. College voor Zorgverzekeringen: Medicijnkosten. [http://www.medicijnkosten.n//]

23. SÚKL - State Institute for Drug Control. [http://www.sukl.eu/]

24. Thériaque. [http://www.theriaque.org/]

25. Informazioni sui farmaci. [http://www.informazionisuifarmaci.it/]

26. AIFA - Agenzia Italiana del Farmaco. [http://www.agenziafarmaco.gov.it/]

27. Royal Pharmaceutical Society, British Medical Association: British National Formulary 65. London: Elsevier Inc; 2013.

28. Belgian Treasury: Reimbursement of Drugs - Performance of Governmental Management. [https:/www.ccrek.be/Docs/2014_02_TerugbetalingGenees middelen.pdf]

29. Picavet $E$, Cassiman D, Simoens S: Do ultra-orphan medicinal products warrant ultra-high prices? A review. Orphan Drugs Res Rev 2013, 3:23-31.
30. Cote A, Keating B: What is wrong with orphan drug policies? Value Health 2012, 15:1185-1191.

31. Schlander M, Beck M: Expensive drugs for rare disorders: to treat or not to treat? The case of enzyme replacement therapy for mucopolysaccharidosis VI. Curr Med Res Opin 2009, 25:1285-1293.

32. Hemphill TA: Extraordinary Pricing of Orphan Drugs: Is it a Socially Responsible Strategy for the U.S. Pharmaceutical Industry? J Bus Ethics 2010, 94:225-242

33. Mycka JM, Dellamano R: ISPOR short course: Elements of Pharmaceutical/ Biotech Pricing. In Proceedings of the ISPOR 13th Annual European Congress, (November 6-9, 2010, Prague, Czech Republic). 2010.

34. Hughes-Wilson W, Palma A, Schuurman A, Simoens S: Paying for the Orphan Drug System: break or bend? Is it time for a new evaluation system for payers in Europe to take account of new rare disease treatments? Orphanet J Rare Dis 2012, 7:74.

35. Picavet E, Dooms M, Cassiman D, Simoens S: Drugs for rare diseases: influence of orphan designation status on price. Appl Health Econ Health Policy 2011, 9:275-279.

36. Kanavos $\mathrm{P}$, Nicod $\mathrm{E}$ : What is wrong with orphan drug policies? Suggestions for ways forward. Value Health 2012, 15:1182-1184.

37. U.S. Food and Drug Administration: FDA Application: Search Orphan Drug Designations and Approvals. [http://www.accessdata.fda.gov/scripts/ opdlisting/oopd/]

38. Simoens S, Picavet E, Cassiman D, Dooms M: What Price do we pay for Repurposing Medicines for Rare Diseases? Value Health 2012, 15:A15-A16.

39. OneSource. [http://www.onesource.com/]

40. European Observatory on Health Systems and Policies: Health Systems in Transition (HiT) series. [http://www.euro.who.int/en/about-us/partners/ observatory/health-systems-in-transition-hit-series]

41. WHO Collaborating Centre for Pharmaceutical Pricing and Reimbursement Policies: Pharmaceutical Pricing and Reimbursement Information (PPRI) Report. [http://whocc.goeg.at/Literaturliste/Dokumente/BooksReports/ PPRI_Report_final.pdf]

42. Martikainen J, Rajaniemi S: Drug reimbursement systems in EU Member States, Iceland and Norway. Helsinki: Belgian Health Care Knowledge Centre; 2002

43. Picavet E, Annemans L, Cleemput I, Cassiman D, Simoens S: Market uptake of orphan drugs - a European analysis. J Clin Pharm Ther 2012, 37:664-667.

44. Morel T, Arickx F, Befrits G, Siviero P, van der Meijden C, Xoxi E, Simoens S: Reconciling uncertainty of costs and outcomes with the need for access to orphan medicinal products: A comparative study of managed entry agreements across seven European countries. Orphanet J Rare Dis 2013, 8:198.

45. Denis A, Mergaert L, Fostier C, Cleemput I, Simoens S: Issues surrounding orphan disease and orphan drug policies in Europe. Appl Health Econ Health Pol 2010, 8:343-350.

46. Genane C, Marinoni G, Reinaud F, Ando G: Impact of Indication Extensions on Pharmaceutical Prices [abstract]. Value Health 2013, 16:A455.

47. Miyamoto BE, Kakkis ED: The potential investment impact of improved access to accelerated approval on the development of treatments for low prevalence rare diseases. Orphanet J Rare Dis 2011, 6:49.

48. European Commission: Regulation (EC) No 141/2000 of the European Parliament and of the Council of 16 December 1999 on orphan medicinal products. Off J Eur Communities 2000, L 18:1-5.

49. Silverman E: Tiger in the Fiscal Room: Beware the Increasing Cost and Number of Orphan Drugs. 2013 [http://www.managedcaremag.com/ archives/1303/1303.orphandrugs.html]

50. Bach PB: Reforming the payment system for medical oncology. JAMA 2013, 310:261-262.

51. Linley WG, Hughes DA: Societal views on NICE, cancer drugs fund and value-based pricing criteria for prioritising medicines: a cross-sectional survey of 4118 adults in Great Britain. Health Econ 2013, 22:948-964.

52. Herper M: The World's Most Expensive Drug. [http://www.forbes.com/ 2010/02/19/expensive-drugs-cost-business-healthcare-rare-diseases.html]

53. Sussex J, Rollet P, Garau M, Schmitt C, Kent A, Hutchings A: A pilot study of multicriteria decision analysis for valuing orphan medicines. Value Health 2013, 16:1163-1169.

54. Vegter S, Rozenbaum MH, Postema R, Tolley K, Postma MJ: Review of regulatory recommendations for orphan drug submissions in the Netherlands and Scotland: focus on the underlying pharmacoeconomic evaluations. Clin Ther 2010, 32:1651-1661. 
55. Kalo Z, Annemans L, Garrison LP: Differential pricing of new pharmaceuticals in lower income European countries. Expert Rev Pharmacoecon Outcomes Res 2013, 13:735-741.

56. Working Group on Mechanism of Coordinated Access to Orphan Medicinal Products (MoCa-OMP): Transparent Value Framework. [http://ec.europa.eu/enterprise/sectors/healthcare/files/docs/ orphans_framework_en.pdf]

doi:10.1186/1750-1172-9-62

Cite this article as: Picavet et al: Shining a light in the black box of orphan drug pricing. Orphanet Journal of Rare Diseases 2014 9:62.

\section{Submit your next manuscript to BioMed Central and take full advantage of:}

- Convenient online submission

- Thorough peer review

- No space constraints or color figure charges

- Immediate publication on acceptance

- Inclusion in PubMed, CAS, Scopus and Google Scholar

- Research which is freely available for redistribution 